\title{
A blueprinting approach to service innovation in private educational institutions
}

\author{
Youn Sung Kim", DonHee Lee ${ }^{1 *}$ (D) and Ju hang $\mathrm{Cha}^{2}$
}

\author{
* Correspondence: \\ dhlee04@inha.ac.kr \\ ${ }^{1}$ College of Business Administration, \\ Inha University, Incheon, South \\ Korea \\ Full list of author information is \\ available at the end of the article
}

\begin{abstract}
This study proposes an efficient service delivery system using a blueprinting approach to service innovation in private educational institutions. This case study presents a flow chart based on administration blueprinting of a private preparatory school for college entrance examination, located in South Korea, to streamline process criteria based on administrative procedures for students and their parents. The results of the case study provide useful planning information for successful implementation of service blueprinting in private educational institutions. The study results are expected to help improve customer encounters as the service provider can employ effective processes. The study also sheds light on new operational management strategies for service innovation. By continuously improving information sharing, service encounters are expected to enhance customer satisfaction. The blueprinting technique can streamline the sequence of customer activities in a service process to meet customer expectations and needs. Thus, the approach could help researchers and administrators as certain how they might implement the system to correct failure points to successfully resolve difficulties.
\end{abstract}

Keywords: Blueprinting approach, Service innovation, Educational institution, Customer satisfaction

\section{Background}

Providing quality service to the customer has been recognized as an essential competitive strategy for business growth in today's uncertain global market environment. Since service quality and customer satisfaction are imperative factors for competitiveness, business firms need a comprehensive approach to accomplish them [1]. In the digital era, service quality concepts have been changed to include "value creation," "quality innovation," and "the service-dominant logic" that should be reflected in the business excellence model to indicate the strategic importance of the customer centric thinking [2]. These concepts will be achieved through an effective process of producing quality goods and services for exceeding customer expectations and experience. Customer expectations and experiences are especially critical for business success in the service industry. As the service sector has evolved to assume a dominant role in economic growth, an increasing emphasis is now placed on the importance of customer expectations [3-5]. In addition, innovation through practical methods can substantially

(c) The Author(s). 2017 Open Access This article is distributed under the terms of the Creative Commons Attribution 4.0 International License (http://creativecommons.org/licenses/by/4.0/), which permits unrestricted use, distribution, and reproduction in any medium, provided you give appropriate credit to the original author(s) and the source, provide a link to the Creative Commons license, and indicate if changes were made. 
improve customer loyalty in service industries [6-8]. Service innovation through exploration of the literature and the available best practice information can help firms achieve sustainable growth [9].

According to Hall et al. [10], "Innovation adoption is a process not a decision point a process that each innovation user experiences individually." The central idea at work here is that innovation is a process rather than an event. To improve operational processes that provide enhanced service through better implementations, organizations must provide a well-designed set of operational processes [11]. Lee [12] suggested that operational innovations in existing work systems and processes are imperative to improve employees' task efficiency for organizational performance.

Previous studies have focused on diagnosing service problems at several levels, including personnel, management, and the supply chain $[8,12]$. Studies have attempted to pinpoint service failures, categorize such failures, and track recovery of service. By analyzing the operational framework in the context of both failures and recovery strategies, a larger operational picture can be captured [13]. Service blueprinting has been widely used to improve operational processes in service industries because it allows for visualization of the service process [7, 8, 14-16].

One of the challenges in private education institutions is to devise a management system that will improve customer (i.e., students and parents) satisfaction. The expectations of students and their parents when shopping around for private educational institutions are focused on the ability of the institution to fully prepare its students for successful professional careers in the future. Thus, educational organizations must be able to satisfy students' long-term needs, not just short-term academic goals.

Tien and Berg [17] presented an idea that customers and service providers can work together to improve value-added or satisfaction in a complex educational system. In service industry as a complex system, process improvement should focus on the customer service quality $[18,19]$. If educational institutions determine the real needs of their customers (students and their parents), they can initiate a value-added process, which will result in long-term benefits to the institutions themselves.

This paper provides a case study to propose an effective way to apply service blueprinting to improving operational processes in the education system. The purpose of the study is to suggest solutions to improve operational processes, such as systemic management of educational institutions. This study also seeks solutions to operating errors that are based on a systematic use of blueprinting. The rest of this paper is organized as follows: the "Review of relevant literature" section presents a review of relevant previous studies; the "Case description" section proposes steps and structure of blueprinting with a case study; and "Discussion and Evaluation" section reports the results and conclusion of the study including limitations.

\section{Review of relevant literature}

\section{Service blueprinting}

Service blueprinting as a flowcharting technique has been used for service process analysis [14]. Shostack [14] defined service blueprinting as "a picture or map that accurately portrays the service system so that the different people involved in providing it can understand and deal with it objectively regardless of their roles or their individual 
point of view." The blueprint also facilitates problem-solving and creative thinking by identifying potential points of failure and highlighting opportunities to enhance customer perceptions of the service [14].

Also, the tool provides a more detailed breakdown of the process into tasks, and it classifies each activity as being either a processing operation, movement, inspection, delay, or a storage based on the existing process [20]. Kim [8] suggested three tools for service process analysis: service package, service blueprint, and quality function deployment. He defines service blueprinting as "a diagram of the service process showing activities, flows, physical evidence, and lines of visibility and interaction."

Service blueprinting indicates the line of visibility between customers and service providers. The line of visibility delineates separated activities between the front office, where customers obtain tangible evidence of the service, and the back office, which is out of the customers' view. The customer requires tangible services and makes evaluations based on the outcomes of those services rather than the process by which they are delivered. The physical separation means that special attention should be paid to the line of visibility, where customer perceptions about effectiveness of service are formed [8].

Service blueprinting is a method that managers can use to make decisions about the inspection and classification of service processes that are in play before the customer gets involved $[8,14,20]$. The method allows services to be preplanned and designed to control processes. Also, it provides managers the opportunity to identify potential failure points and to redesign procedures to avoid such occurrences, thus ensuring the delivery of high-quality service [21]. This tool can help lead to not only prioritizing tasks, reduction of movements, and simplification of work but also identifying opportunities to create work processes or use flow processing more efficiently for task activities based on an existing process [21].

Since most service is dynamic, service production can be delivered by a sequence of identified activities. The service production flow in a poorly designed system leads to delivery errors or communication problems. To prevent these problems, service blueprinting as a flow chart has been effectively employed.

Shostack [22, 23] suggested service blueprinting for process analysis to modify shoe repair and discount brokerage services. Lovelock and Vandermerwe [24] showed the application of service blueprinting to hotel, bank, and florist services. Kumar et al. [25] reported improvements in operational processes using service blueprinting in an online business, Bellacor. The result of the study showed that the proposed blueprinting improved customer service and delivery tracking, reduced errors, and provided a better overall experience to the customer [25].

\section{Components of service blueprinting}

A new comprehensive set of symbols (Fig. 1) is compiled for this study based on literature review of service blueprinting and service mapping. Appropriate symbols can be selected from this set with respect to suitability and applicability in customizing the application of service blueprinting for particular processes. The main factors of service blueprinting include customer action, activities of the front office and back office, and supporting processes. There is no standardized type of service blueprinting. 


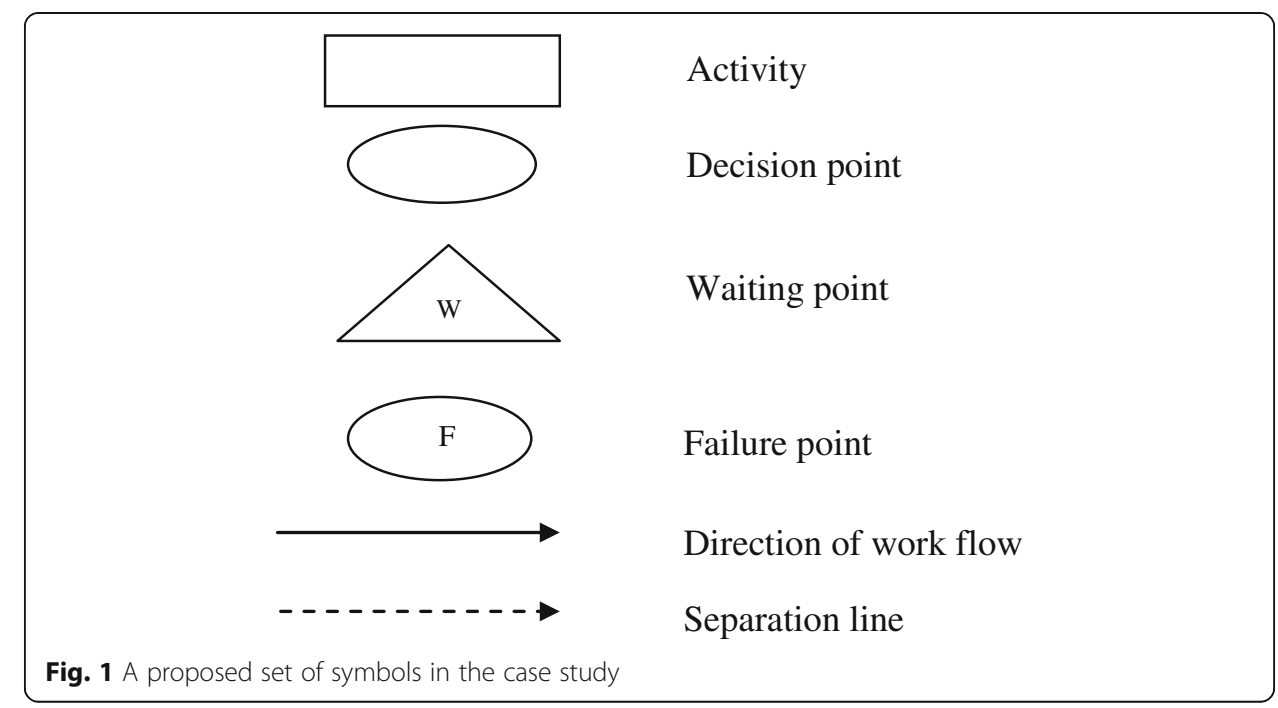

The symbols or the number of levels used may be explained differently by the user or based on the complexity of the application area. In other words, the symbols may indicate different things depending on the uniqueness of what is represented.

Bitner et al. [7] proposed "applying blueprinting in practice" as a guideline as follows: (1) decide on the company's service or service processes to be blueprinted and the objective, (2) determine who should be involved in the blueprinting process, (3) modify the blueprinting technique as appropriate, (4) map the service as it happens most of the time, (5) note disagreements to capture learning, (6) be sure customers remain the focus, (7) track insights that emerge for future action, and (8) develop recommendations and future actions based on blueprinting goals and, if desired, create final blueprints for use within the organization.

There are five components of a typical service blueprint: "customer actions, onstage/visible contact employee actions, backstage/invisible contact employee actions, support processes, and physical evidence" [7]. In our case study, we used four components of the typical service blueprinting: customer actions, visible contact frontline workers, invisible contact back-office workers, and the supporting process. Customer activities include all steps of customer actions (e.g., ask for service, provide information), choice, and interactions in processes of purchase, consumption, and assessment. Employee activities can be grouped into two generic approaches: frontline workers and back-office staff.

Frontline workers in visible contact points directly provide service to customers in the line of visibility through their responsibility to direct service, but they have little choice in the operational process for customer satisfaction. Back-office staff makes preparations for the service of customers, which is then carried out by the frontline workers. Back-office workers do not have direct interactions with customers as their role is to perform actions that are beyond the customers' line of visibility. For example, the activities of an employee who places phone calls with physicians in order to prepare care services are performing support activities for contact point workers.

The supporting process is an internal process by which services are delivered, for instance, an education center that provides employees' skills and competency 
development. There is a difference between components of blueprinting and differentiation of other service processes because blueprinting encompasses customer actions and customer views reflected by the service process.

\section{Case description}

\section{Planning of service blueprinting analysis}

To illustrate the application of service blueprinting, a private educational institution was chosen. The institution is located in Incheon, South Korea. The institution is a private preparatory school for college entrance examination and is located on the fifth floor of a large building. There are 45 staff members working in the institution. A questionnaire was developed based on existing blueprinting of the institution and past accounts of service failures. Students, parents, and employees were then contacted for interviews. As operational failures in the education system cause reduction in the number of new or re-registered students, the study proposed to redesign and correct procedures for continued improvement of operational processes through service failure factors.

This case study was undertaken using the following criteria, based on administrative procedures for the students and parents at the institution and through benchmarking the best practices of service systems of educational institutions: (1) a customer-oriented service delivery system is the primary goal of the service provider (e.g., service quality of the instructor and/or consultant), and (2) the development process of the system considered various needs of students and parents including the desired service quality and quantity of instructors and consultants.

To develop an appropriate service delivery system, first, a suitable design and analysis for the system must be defined as shown in Table 1. The process used in the case is as follows: (1) the logical sequence of service delivery for each stage, (2) issues pertaining to service delivery system flexibility, and (3) problems involved in interactions between customers and providers. A more detailed summary of the above processes in the institution is shown in Table 1.

Table 1 Guideline and procedure for service blueprinting

\begin{tabular}{ll}
\hline Classification & Contents \\
\hline Logical sequence of service delivery system & -Logical and sequential array of admission and registration \\
& processes by visiting students and parents \\
& -Help saving time \\
& -Easily understandable service processes \\
& -Predictable service processes \\
& -Prepare admission and registration processes based on \\
Flexibility of service delivery system & differences of opinion between students and parents \\
& (e.g., admission procedure for registered, unenrolled, \\
and new student) & \\
Interaction between customers and providers & -Establish the system to effectively deliver services \\
& -For example: \\
& - A student went to the wrong classroom for the first class. \\
& - A student could not follow changes mode for class \\
meeting locations or times. & - Class schedule reliably notes the name of the teacher \\
& school bus or other transportation is reliable and consistent.
\end{tabular}




\section{Key points of service blueprinting analysis}

With differentiations in lecture quality, service, reputation or image, and instructional resources, the study focused on new blueprinting to improve educational quality in the private institution. Thus, the study attempted to understand, analyze, and ultimately solve problems for the satisfaction of students and parents. Specially, composition of service blueprinting was based on the expected problems or issues as follows:

(1) Measurement and analysis of the perceptions of students, parents, and other stakeholders

(2) Measurement and analysis of information management

(3) Management of information and knowledge

(4) Development of the blueprinting manual and quarterly reports based on work processes

(5) Motivation for blueprinting by all staff

(6) Staff perception on blueprinting for education and training

(7) Design of blueprinting based on the desires of students, parents, and stakeholders

\section{Procedure of service blueprinting}

Most parents and students have increased their expectations about educational service of private institutions. It is important that the leaders of the private educational institutions strive to meet or exceed customer expectations. Consequently, they must improve educational service with service measurements by utilizing new methods such as blueprinting. An increased use of blueprinting would lead to developing a process manual of service activities that can improve service quality in the educational industry.

The process of this case study is as follows: (1) activity flows of registered students and parents are developed by blueprinting with staff; (2) the basic blueprinting is reviewed by frontline workers and then problems and improvements are reported; (3) a revised blueprinting is developed based on the previous step; and (4) new improvements are suggested through repetition of the above process.

\section{Discussion and evaluation}

The first step toward successful service is to present a favorable impression that leads to registration when customers, as students and parents, visit a private academy for the first time. Thus, process analysis and evaluation of all activities of customers, from the first visit all the way to return home, and improving service quality are critical success factors. A process flow chart of visits, consultations, registration, and returning home is compiled and analyzed in the case study.

\section{Improvement of blueprinting from visit to return}

There are several steps from a visit of a private preparatory institution to returning home as shown in Fig. 2 and below:

(1) Customers at the parking lot

(2) Take an elevator

(3) Get off the elevator to enter the central hall 


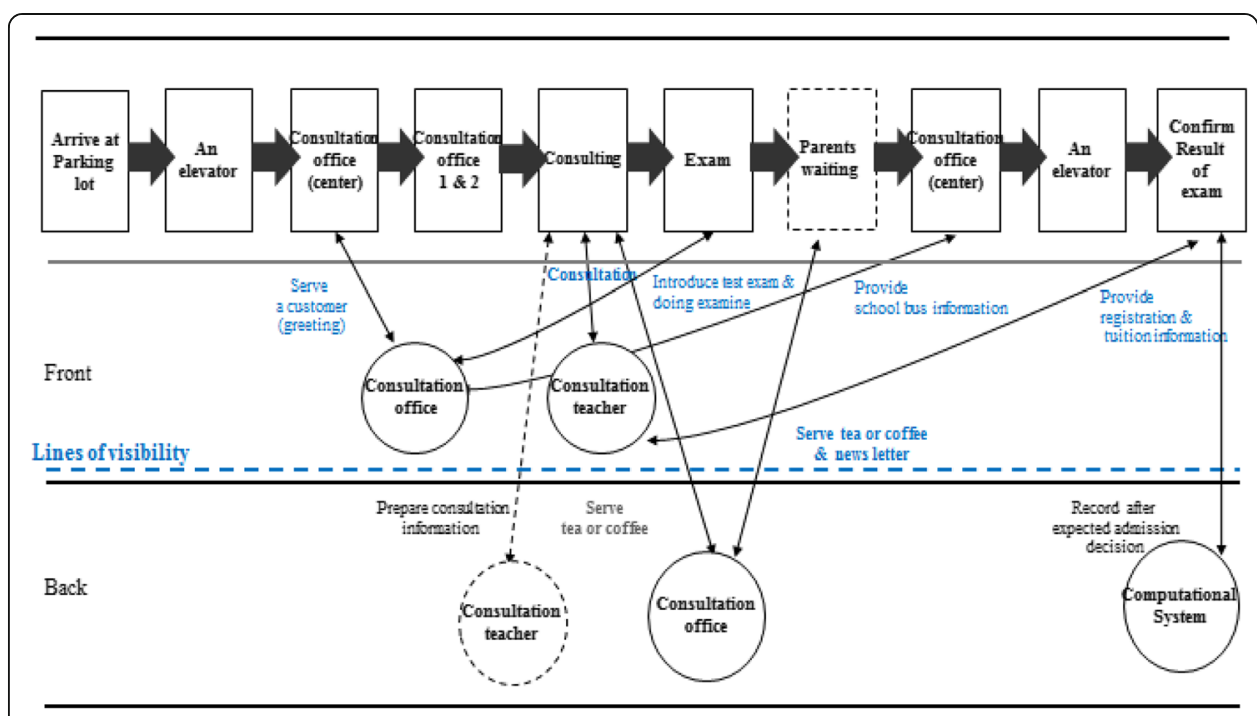

Fig. 2 Basic blueprinting of the flow chart from visit to return

(4) Enter the consultation office and then fill out an application

(5) Students who want to enter the school take an admission examination

(6) Parents wait for their son or daughter during the examination

(7) Students and parents ride an elevator to return to the parking lot

(8) After coming back home, the customer waits for an admission letter based on results of the visit and exam

Several problems are pointed out above. As shown in Fig. 3 and Table 2, waiting for an elevator is boring to customers, and the customer is waiting at F1 point. Customers can be embarrassed at the entering point, which is F2, when a counselor does not properly receive the customer. Unlike expectations, if there is a need consultation, waiting time is boring to customers and the consultation is pointed out as a waiting problem F3. When parents wait for their son or daughter during the examination, classroom may show some undesirable features as F4, since parents can see a lecture through a monitor.

\section{Improvement of blueprinting for new students}

The successful service should result in customers receiving a positive impression and students register for the first time. Thus, process analysis and evaluation of all activities are needed for new registered students. A process flow chart for new students from registration to return home is compiled as shown in Fig. 4.

There are several steps for new registered students of a private preparatory institution as shown below and in Fig. 4:

(1) Arrive at the private preparatory institution

(2) Take an elevator to arrive at the fifth floor

(3) Register in the consultation office

(4) Insert a face photo 


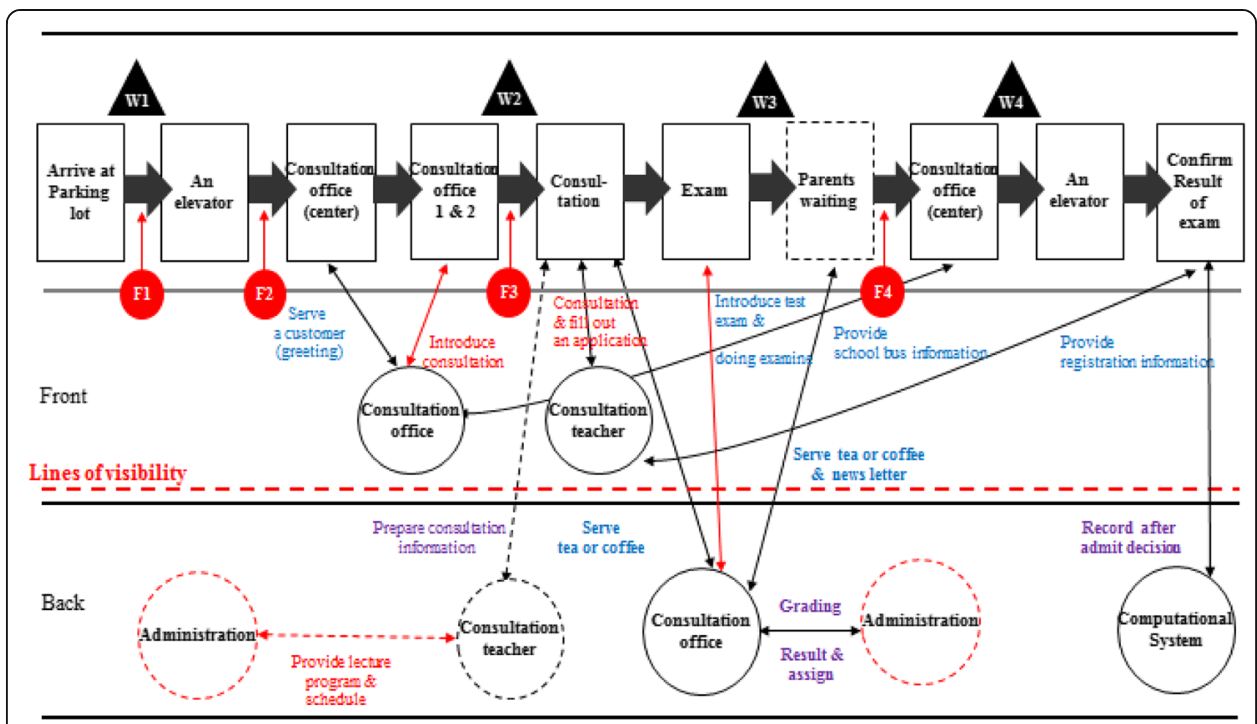

Fig. 3 Revised blueprinting on flow chart of from visit to return

(5) Record fingerprints for attendance

6) Provide textbooks and classroom notices

(7) Introduce the homeroom teacher

(8) Attend a lecture

(9) Return home on a school bus

There is a waste of time when the students need to wait to do any of the above process steps. W1 is an elevator waiting time when entering. W2 and W3 are processes to go to a classroom after registration and fingerprinting in the consultation office. W4 is a step to check the classroom notice after receiving textbooks and materials. W5 is an elevator waiting time to return home. There are service failure points throughout service processes as shown in Fig. 5. New blueprinting is developed for new students from registration to returning home as shown in Fig. 5.

As shown in Fig. 5 and Table 3, there are several problems possible in the process flow chart for new students from registration to returning home. The registration process might be ignored by readmitted students because they can go directly to the classroom instead of the consultation office (F1). If students do not understand the admission process, it can be confusing (F2). Even if the classroom is correctly noted, students could take a class in a different room (F3). To prevent the above listed problems, a rechecking process after the first class is needed, so it represents a failure

Table 2 Failure points and waiting from visit to return blueprinting on flow chart

\begin{tabular}{|c|c|c|c|}
\hline \multicolumn{2}{|c|}{ Failure points } & \multicolumn{2}{|c|}{ Waiting } \\
\hline F1 & With only 3 elevators working, many people wait for elevators & W1 & Waiting for an elevator \\
\hline F2 & $\begin{array}{l}\text { Customers can be embarrassed at the entering point, } \\
\text { when a counselor cannot figure out lading customers } \\
\text { to the consultation office }\end{array}$ & W2 & $\begin{array}{l}\text { Waiting consultation document } \\
\text { and task arrangement }\end{array}$ \\
\hline F3 & A long waiting line because of busy office & W3 & Waiting time during the exam \\
\hline F4 & $\begin{array}{l}\text { Classroom may show some undesirable features, } \\
\text { when parents see a lecturer on a monitor }\end{array}$ & W4 & Waiting for an elevator to return \\
\hline
\end{tabular}




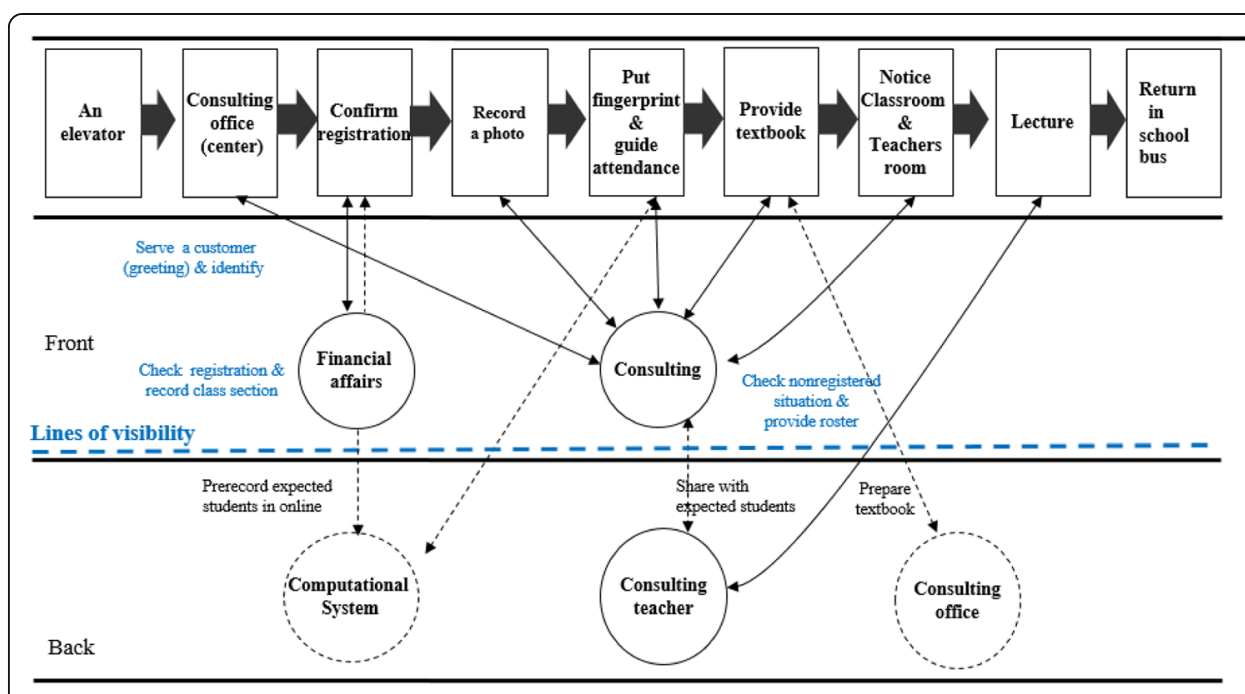

Fig. 4 Basic blueprinting for new students from registration to return

point (F4). Finally, school bus ride complications based on incomplete documentation or administrative communication as F5.

\section{Practical applications based on the case study}

To resolve or suggest solutions to the above problems based on practical applications, the case study provides several suggestions. First, one of the three elevators be reserved exclusively for the institute directly from the first floor to the fifth floor to save waiting time and improve convenience. Today's class time and room numbers should be posted for easy reference for students on the first floor; also, it can reduce boring time to wait for an elevator. The institute should open the whole process as a flow chart or a figure for easy reference on the first floor and provide a comfortable room with beverages, computers, or a television for parents not to have boring time during the exam of their son or daughter. To prevent any student taking a wrong class in a different room, a

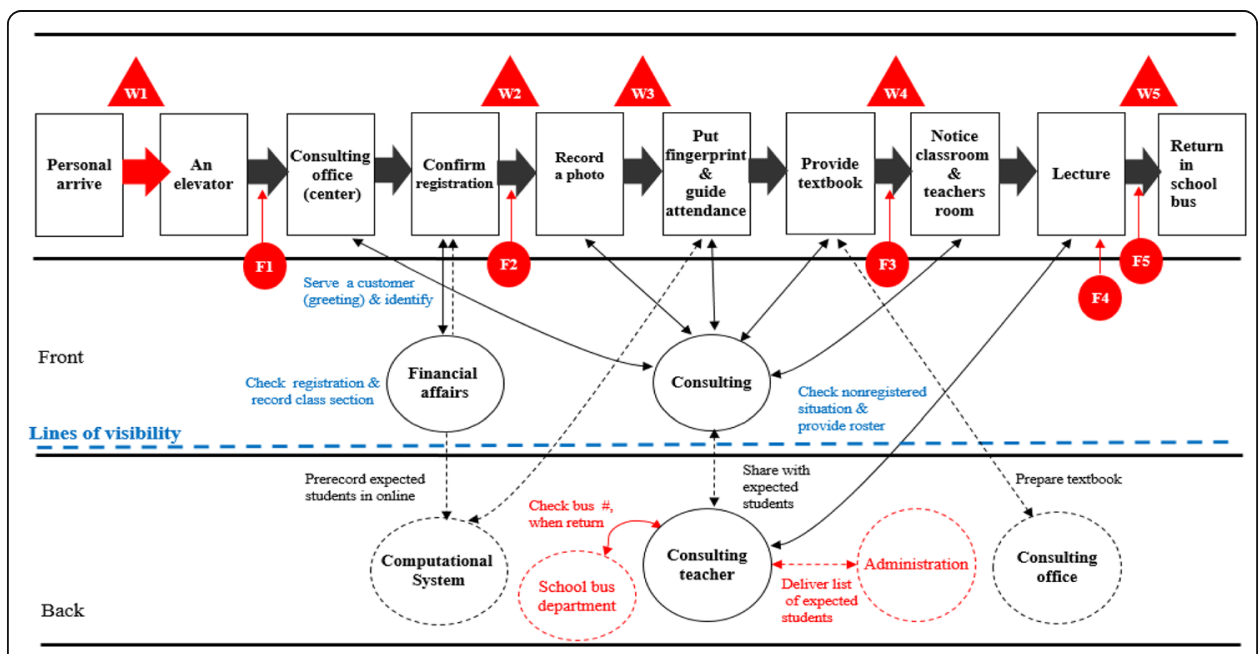

Fig. 5 Improved blueprinting for new students from register to return 
Table 3 Failure points and waiting from register to return blueprinting on flow chart

\begin{tabular}{llll}
\hline Failure points & Waiting & \\
\hline F1 & $\begin{array}{l}\text { Readmitted students can go directly the classroom } \\
\text { (unregistered situation, unpaid tuition) } \\
\text { - missing on the list of expected students because of } \\
\text { decided to register late }\end{array}$ & W1 & Waiting for an elevator \\
F2 & $\begin{array}{l}\text { Students with unpaid tuition and/or possible registration } \\
\text { of the new or readmitted students }\end{array}$ & W2 & Waiting to record a photo \\
F3 & $\begin{array}{l}\text { Potential students can take a class in different class } \\
\text { F4 }\end{array}$ & W3 & Weed a process rechecking after first class and a \\
possible changed class & W4 & Waiting to get fingerprinted \\
F5 & $\begin{array}{l}\text { Cannot ride private school bus } \\
\text { (missing on the list of new students) }\end{array}$ & W5 & $\begin{array}{l}\text { Waiting for an elevator to } \\
\text { return home }\end{array}$ \\
\hline
\end{tabular}

manager or a leader should provide new information to students using text massages to cell phones at least $1 \mathrm{~h}$ in advance. Renovations and/or rearrangements of offices may need in order to facilitate a better flow of traffic based on waiting lines at the consultation office to record a photo and fingerprinting. For the staff, a manager or a leader should provide work guidelines and information about the duties of back-office workers vs. front-office workers (teachers or administrative support) who have direct contacts with customers, to improve satisfaction of customers and staff, increase student performance on exam or lecture, and support staff or students through quality service to maximize mutual benefits.

Since it is important to increase the number of students, professional counseling should be provided based on students' performance and their parents' expectation as well as available classes. A leader should encourage the administrative staff not to overbook consultation appointments with parents to have enough time for internal communication. From a temporal standpoint for students, a leader should provide the best experience educational opportunities (e.g., memorize, review, or time schedule) to prepare for exams or lectures.

\section{Conclusions}

Operational innovation improves organizational processes that are needed for effective and seamless interactions among teachers, administrators, and student as customers in academic institution. Also, operational innovation can support reduction in lead time and consistent educational service quality [12]. Thus, educational institution should promote operational innovation to search for new opportunities for customer value creation using the blueprinting approach.

This paper presents our experiences with a case study where the blueprinting approach was used to improve service quality in a private educational institution. The results of this study are expected to help improve customer encounters as the service provider can employ useful processes. As shown above, sharing the information with employees improves work efficiency cooperation among departments and decisionmaking. Therefore, by continuously improving information sharing, work efficiency is expected to improve.

Also, the primary functional lines should be clearly developed to facilitate speedy analysis of stakeholders in the process for the success of the organization. The line of 
visibility provides the process analyzer to improve each encounter to take advantage of both the lines of external and internal interactions.

There are some limitations of the study. First, this study used activities on the line of visibility and focused on administrative services. Second, the case study did not consider different delivery times of services in a more detailed way based on the type of service. Finally, this study assumed that private educational institutions provide basically the same service. Future research should consider these limitations and further explore different service activities, capability of staff members, and differences between new and readmitted students based on the level of education.

Authors' contributions

All authors contributed to the developing research model, data collection, and writing of the manuscript.

Competing interests

The authors declare that they have no competing interests.

\section{Author details}

${ }^{1}$ College of Business Administration, Inha University, Incheon, South Korea. ${ }^{2}$ Education AS, Incheon, South Korea.

Received: 5 September 2016 Accepted: 3 February 2017

Published online: 02 March 2017

\section{References}

1. Ngo L, O'Cass A (2010) Value creation architecture and engineering-a business model encompassing the firmcustomer dyad. Eur Bus Rev 22(5):496-514

2. Lee $S$ (2015) The age of quality innovation. Int J Quality Innov 1:1-5

3. Crosby L, Johnson S (2007) Experience required. Mark Manag 16(4):20-28

4. Meyer C, Schwager A (2007) Understanding customer experience. Harv Bus Rev 85(2):117-126

5. Rosenbaum M, Wong I (2009) Modeling customer equity, SERVQUAL, and ethnocentrism: a Vietnamese case study. J Serv Manag 20(5):544-560

6. Hauser J, Tellis G, Griffin A (2006) Research on innovation: a review and agenda for marketing science. Mark Sci 25(6):687-721

7. Bitner MJ, Ostrom AL, Morgan FN (2007) Service blueprinting: a practical technique for service innovation. Center for Services Leadership, Arizona State University. Working Paper

8. Kim Y (2011) How to teach the service process analysis tools. 22th Annual POMS conference, Reno, NV.

9. Tidd J, Hull F (2003) Service innovation: organizational responses to technological opportunities and market imperatives. Imperial College Press, London

10. Hall G, Loucks S, Rutherford W, Newlove B (1975) Levels of use of the innovation: a framework for analyzing innovation adoption. J Teach Educ 26(1):52-56

11. Fisher B, Kenny R (2000) Introducing a business information system into an engineering company. InformationKnowledge-Systems Management 2(2):207-221

12. Lee D (2015) The effect of operational innovation and QM practices on organizational performance in the healthcare sector. Int J Quality Innov 1(8):1-14

13. Johnstone R, Michel S (2008) Three outcomes of service recovery: customer recovery, process recovery and employee recovery. Int J Oper Prod Manag 28(1):79-99

14. Shostack G (1982) How to design a service. Eur J Mark 16(1):49-63

15. Fließ S, Kleinaltenkamp M (2004) Blueprinting the service company-managing service processes efficiently. J Bus Res 57(4):392-404

16. Geum Y, Park Y (2011) Designing the sustainable product-service integration: a product-service blueprint approach. J Clean Prod 19(14):1601-1614

17. Tien J, Berg D (2003) A case for service systems engineering. J Syst Sci Eng 12(1):13-38

18. Senge $P(1990)$ The fifth discipline: the art and practice of the learning organization. Doubleday, NY

19. Winn R, Green R (1998) Applying total quality management to the educational process. Int J Eng Educ 14(1):24-29

20. Martinich J (1997) Production and operations management: an applied modern approach. John Wiley \& Sons Inc., NY

21. Fitzsimmons J, Fitzsimmons M (1999) Service management-operations, strategy, and information technology, 2nd edn. Irwin/McGraw-Hill, NY

22. Shostack G (1984) Designing services that deliver. Harv Bus Rev 62(1):133-139

23. Shostack G (1987) Service positioning through structural change. J Mark 51(1):34-43

24. Lovelock C, Vandermerwe S, Lewis B (1999) Services marketing: a European perspective. Prentice Hall Europe, UK, Hemel Hempstead

25. Kumar S, Hudson B, Lowry J (2010) Consumer purchase process improvements in e-tailing operations: a case study. Int J Product Perform Manag 59(4):388-403 